TITLE:

\title{
Cr as a key factor for direct synthesis of multi-walled carbon nanotubes on industrial alloys
}

$\operatorname{AUTHOR}(\mathrm{S})$ :

Sano, Noriaki; Yamamoto, Suguru; Tamon, Hajime

CITATION:

Sano, Noriaki ... [et al]. Cr as a key factor for direct synthesis of multi-walled carbon nanotubes on industrial alloys. Chemical Engineering Journal 2014, 242: 278-284

ISSUE DATE:

2014-04

URL:

http://hdl.handle.net/2433/182078

RIGHT:

(c) 2014 Elsevier B.V.; This is not the published version. Please cite only the published version.; この論文は出版社版でありません。引用の際に は出版社版をご確認ご利用ください。 


\title{
$\mathrm{Cr}$ as a key factor for direct synthesis of multi-walled carbon nanotubes on industrial alloys
}

\author{
Noriaki Sano ${ }^{*}$, Suguru Yamamoto, Hajime Tamon \\ Department of Chemical Engineering, Kyoto University, Nishikyo-ku, Kyoto, 615-8510, Japan
}

Key words: Carbon nanotube; Alloy; Chemical vapor deposition; Stainless steel

Abstract Six kinds of industrial alloys, SUS316, FCH2, Invar, Permalloy, Inconel, and Nichrome, and three kinds of pure metals, $\mathrm{Fe}, \mathrm{Ni}$, and $\mathrm{Cr}$, were used for substrates on which multi-walled carbon nanotubes (MWCNTs) were directly synthesized from ethylene. To activate their surfaces for the MWCNT formation, their surfaces were modified by two steps, (1) oxidation step in Ar- $\mathrm{O}_{2}$ mixture gas and (1) following reduction step in $\mathrm{Ar}-\mathrm{H}_{2}$ mixture gas. It was discovered that $\mathrm{Cr}$ is a key component to realize the catalytic growth of MWCNTs on Fe and Ni emerged from the alloys. Using SUS316 to observe the influence of oxidation duration on MWCNT diameter, it was seen that increasing the oxidation duration resulted in the increase of the MWCNT diameter. This tendency can be explained by diffusion of Fe through Cr-rich layer, which causes the increase of catalyst particle diameters. The excess Fe diffusion through the Cr-rich layer resulted in the formation of a unique mushroom structure. These effects seen in the observation on the oxidation duration did not appear when reduction duration was prolonged because the Cr-rich layer could inhibit the Fe diffusion. Instead, the length of the MWCNTs can became maximum by employing an appropriate reduction duration.

* Corresponding authors. Tel.: +81 75 3832684; fax: +81 753832654 (N. Sano) E-mail addresses: sano@ cheme.kyoto-u.ac.jp (N. Sano) 


\section{Introduction}

Carbon nanotubes (CNTs) [1] are attractive materials among functional carbon materials due to their superior properties for many kinds of applications [2-6], and numerous researches about fundamentals in physical and chemical characteristics have been investigated [7-12]. Under such circumstances, variety of techniques to synthesize CNTs have been highly developed [13-23]. In early times, techniques using arc discharge [13-16] and laser ablation [17-19] seemed to be common to synthesize nanotube-family materials. Lately, techniques using chemical vapor deposition (CVD) on substrate surfaces have been studied intensively [20-28] so that controllability of the product structure, purity, and yield have been significantly improved.

When the CVD method is applied to synthesize CNTs on solid surfaces, catalyst loading process is first necessary in many conventional cases [20,21]. Nevertheless, CNTs could be synthesized by CVD directly on stainless steel surface without this delicate catalyst-loading step by employing a simple surface treatment using an oxidation followed by a reduction. This method can be considered to be superior in terms of simplicity and ability to produce CNTs on surfaces of complicated-shapes [24-26]. For example, CNTs were synthesized on inner surfaces of porous stainless steel block [26] or on fine stainless steel meshes [25] using this method, despite that catalyst loading on such complicated surfaces by conventional processes can hardly be carried out. One may speculate that not only stainless steel surface but also the surfaces of other kinds of alloys can be activated to synthesize MWCNTs by the same manner. When various alloys are used, new MWCNT-metal composite materials having 
superior properties for some applications would be created because physical properties of alloys should uniquely vary with their components [29].

To develop such MWCNT-metal composite materials, one must know fundamental key factors in synthesis of MWCNTs on alloy surfaces. In the present study, six kinds of alloys used for various fields of industries and three kinds of pure metals were used as substrates to explore a key factor to realize the MWCNT growth on various kinds of alloys. Furthermore, durations of oxidation step and reduction step were varied to observe their effects. This observation also could help ones to consider important factor to control the product structures.

\section{Experimental}

Plates (thickness $=0.5 \mathrm{~mm}$ ) of six kinds of industrial alloys, stainless steel SUS316, Japanese Industrial standards FCH2, Invar ${ }^{\circledR}$, Permalloy ${ }^{\circledR}$, Inconel ${ }^{\circledR}$, and Nichrome ${ }^{\circledR}$ were purchased from Niraco Co. to use as the substrates to synthesize MWCNTs on their surfaces. SUS316 and Inconel are known as materials which are stable against corrosion. $\mathrm{FCH} 2$ and Nichrome are designed to be used for resistance wire for heating devices. Invar has uniquely low coefficient of thermal expansion. Permalloy is a non-oriented alloy having high core gain requirements of magnetic preamplifiers and modulators. In addition, three kinds of pure metals, $\mathrm{Fe}, \mathrm{Ni}$, and $\mathrm{Cr}$, which are main components of these alloys, were use as substrates. These plates were cut to make square plates of $1 \mathrm{~cm}$ side. The surfaces were cleaned by ethanol without any chemical treatment.

The surface treatment on these plates were performed by two steps, oxidation and reduction steps. 
$[25,26]$ In first step, the plates were heated to $800{ }^{\circ} \mathrm{C}$ in $\mathrm{Ar}-\mathrm{O}_{2}$ gas mixture (Ar flow rate $=400 \mathrm{cc} \mathrm{min}^{-1}$,

$\mathrm{O}_{2}$ flow rate $=100 \mathrm{cc} \min ^{-1}$ ) in a quartz tube placed in a electric furnace. The duration of this step was varied from $10 \mathrm{~min}$ to $2 \mathrm{~h}$. In the second step, the gas components were switched to $\mathrm{Ar}-\mathrm{H}_{2}$ mixture (Ar flow rate $=120 \mathrm{cc} \mathrm{min}^{-1}, \mathrm{H}_{2}$ flow rate $=360 \mathrm{cc} \mathrm{min}^{-1}$ ) and the temperature was increased to $820{ }^{\circ} \mathrm{C}$ so that the oxidized surfaces of the plates were reduced. The duration of the reduction step was varied from 0 to $2 \mathrm{~h}$. After this reduction step, ethylene $\left(\mathrm{C}_{2} \mathrm{H}_{4}\right)$ was admixed to this gas mixture $\left(\mathrm{C}_{2} \mathrm{H}_{4}\right.$ flow rate $=35 \mathrm{~cm}^{3} \min ^{-1}$, Ar flow rate $=120 \mathrm{cc} \mathrm{min}^{-1}, \mathrm{H}_{2}$ flow rate $=360 \mathrm{cc} \mathrm{min}^{-1}$ ) keeping this temperature to grow MWCNTs for $1 \mathrm{~h}$. After cooling down to room temperature with purging gas (Ar), the plates were collected for analyses.

A scanning electron microscope (SEM) (JEOL, JSM-6701F) and a transmission electron microscope (TEM) (JEOL, JEM-2010) were used for microscopic analyses on the products. An energy dispersive X-ray (EDX) (Technex, Tiny-EDXS(LE)) was used to measure the atomic ratio of the components in the alloys. X-ray photoelectron spectroscopy (XPS) (Shimadzu Co., ESCA-3400) was used to observe the component distribution in depth direction on SUS316 surface to observe the influence of oxidation treatment. The crystalline perfection of MWCNTs were evaluated by a Raman spectroscopy (Raman Systems, R-3000).

\section{Results and discussion}

\subsection{Key role of Cr in alloy surfaces for MWCNT growth}

Components in the pristine alloy plates used in the present study were analyzed by EDX as shown 
in Fig. 1. As seen in this figure, four kinds of alloys, FCH2, SUS316, Inconel, and Nichrome, included similar percentages of $\mathrm{Cr}$. Unlike these alloys, Invar and Permalloy did not contain significant amount of $\mathrm{Cr}$. A trace of impurities were detected by EDX in the plates of $\mathrm{Ni}$ and $\mathrm{Cr}$, but Fe seemed to be high purity.

The morphologies of the substrate surfaces were analyzed at the three stages, (1) after reduction step, (2) after oxidation step and (3) after CVD for MWCNT growth. SEM images of the plate surfaces of $\mathrm{Fe}, \mathrm{Ni}$, and $\mathrm{Cr}$ are shown in Figs. 2. By visual observation, the color of the plates of $\mathrm{Fe}$ and $\mathrm{Ni}$ became black after the CVD step, suggesting that carbonaceous products were produced on Fe and Ni. However, MWCNTs were not observed as shown in Figs. 2. It can be seen that the surfaces became porous by melting the oxidized domains after the oxidation and reduction steps. The color of $\mathrm{Cr}$ plate did not become black but gray, suggesting that there was no carbonaceous product produced. The morpholoy of the $\mathrm{Cr}$ surface after the oxidation and reduction steps seemed to be similar to case of $\mathrm{Ni}$ in the SEM observation. The results shown here suggest that the surface of Fe and Ni had an ability to promote dissociation of $\mathrm{C}_{2} \mathrm{H}_{4}$ to form carbonaceous products after the oxidation-reduction surface treatment, but did not have the effect to form MWCNTs. It is well known that nanoparticles of Fe and $\mathrm{Ni}$ have catalytic effect to dissolve carbon from organic gases to re-precipitate into tubular structures [30]. It should be noted that MWCNTs can not be formed unless $\mathrm{Fe}$ and $\mathrm{Ni}$ are discrete into nanoparticles. However, the reduction of the surfaces of the plate of pure Fe or Ni should lead to the formation of large grain of $\mathrm{Fe}$ or $\mathrm{Ni}$, which can dissolve carbon from $\mathrm{C}_{2} \mathrm{H}_{4}$ but did not form MWCNTs. 
The present result also suggests that $\mathrm{Cr}$ does not have catalytic ability to dissolve carbon from $\mathrm{C}_{2} \mathrm{H}_{4}$ even when the surface modification was performed by the oxidation-reduction steps.

Also the microscopic images of the surfaces of Invar and Permalloy are shown in Fig. 2. The results from Invar and Permalloy were substantially same as those from $\mathrm{Fe}$ and $\mathrm{Ni}$, in which carbonaceous products were produced but MWCNTs were not synthesized. Because the main components of both Invar and Permalloy are $\mathrm{Fe}$ and $\mathrm{Ni}$, their surfaces should have reactivity to decompose $\mathrm{C}_{2} \mathrm{H}_{4}$ to re-precipitate carbonaceous products as seen in the results using the plates of $\mathrm{Fe}$ and Ni. However, due to the result that MWCNTs were not synthesized, one can consider that the nanoparticles of Fe and Ni should not appear on their surfaces.

Figs. 3 shows the results of a set of the four alloys including Cr. Main component of FCH2 and SUS316 is Fe, and that of Inconel and Nichrom is Ni. It is important to note that MWCNTs were synthesized on all of these alloys. One can see the morpholoy change of their surface after the oxidation step, in which the roughness on their surfaces seems to be much finer compared with the cases in Fig. 2. The roughness on their surfaces after reduction step also seems to be finer than on the surfaces in Fig. 2.

The results shown in Figs. 2 and 3 can suggest that $\mathrm{Cr}$ must have a key role to realize the direct growth of MWCNTs on the alloy surfaces. Because the catalyst to grow MWCNTs in any CVD process need to be discrete into nano-size particles, $\mathrm{Cr}$ should have a role to stably support the $\mathrm{Fe}$ and $\mathrm{Ni}$ nanoparticles in discrete forms. 
The Raman spectra were obtained from MWCNTs produced on the surface of above alloys on which MWCNTs were synthesized. Fig. 4 shows the relative intensities of peaks corresponding to the disorder structures and graphite structures, respectively at about $1350 \mathrm{~cm}^{-1}$ (D-peak) and $1600 \mathrm{~cm}^{-1}$ (G-peak). In many cases reported, the ratio of the intensities of D-peak to that of G-peak (D/G ratio) are compared, by which the crystalline perfection can be considered low when D/G ratio is high. In the spectra in Fig. 4, the intensity of $\mathrm{D}$ peak is comparative to that of G peak with variation of D/G ratio within 0.8 -1.2. There is no relation of the main components ( $\mathrm{Fe}$ or $\mathrm{Ni}$ ) to $\mathrm{D} / \mathrm{G}$, and also the influence of the concentration of $\mathrm{Cr}$ is not seen.

\subsection{Contribution of Cr layer to support catalytic Fe nanoparticles to determine MWCNT structures}

The influence of oxidation duration on the structure of MWCNTs was investigated by SEM observation. In this observation, the temperatures for oxidation step, reduction step, and CVD were 800, 700 , and $700{ }^{\circ} \mathrm{C}$, respectively. The thickness of the MWCNT film seem to be independent of the oxidation duration, showing that the MWCNT film thickness was approximately $20 \mathrm{~nm}$ as shown in Fig. 5a. Nevertheless, their diameter was dependent on the oxidation duration obviously, as plotted in Fig. 6 based on the observation using TEM. An example image obtained by TEM is shown in an inset of Fig. 6, confirming that the products have hollow tubular structures. The plots reveal that the diameter tends to become larger when the oxidation duration increases.

This result can be explained by the diffusion of Fe through an oxidized $\mathrm{Cr}$ layer existing on the 
SUS316 surface. When the diameter of MWCNTs increases, catalyst nanoparticles must be larger. In the present case, the catalyst particles should be the nanoparticles of Fe because the dominant component in SUS316 is Fe. It was reported that Fe can diffuse through the surface layer of oxidized Cr of stainless steel toward outermost surface at a elevated temperature [31] so that amount of Fe at the outermost surface increases. Then, it is reasonable that the Fe nanoparticles at the outermost surface should grow to become large particles when Fe reaches there by this diffusion. By this growth of the Fe particles, the diameter of MWCNTs should increase.

The XPS results analyzing $\mathrm{Fe}, \mathrm{Ni}, \mathrm{Cr}, \mathrm{O}$, and some impurities at the SUS316 surface layer with varied etching time is shown in Fig. 7. It is suggested that there are substantial profiles in concentrations of some components, $\mathrm{Fe}, \mathrm{Cr}$, and O, at the SUS316 surface in depth direction, although the variation in the concentrations of $\mathrm{Ni}, \mathrm{Mn}, \mathrm{Mo}$, and Co are not significantly seen. It is seen that after $1 \mathrm{~h}$ of oxidation step when the MWCNTs can grow on the SUS316 surface well, by which the morphology of the resulted MWCNTs can become similar to Fig. 5a, the concentrations of $\mathrm{Cr}$ and $\mathrm{O}$ at the surface layer are obviously high. However, after $2 \mathrm{~h}$ of the oxidation step, Fe diffuse to the outermost surface through the oxidized $\mathrm{Cr}$ layer and the concentration of Fe significantly increases. On the other hand, $\mathrm{Cr}$ concentration decreases to negligible level. In such a condition, the discrete Fe nanoparticles can not be generated by the reduction step because the outermost surface of SUS316 is entirely covered with oxidized Fe. Then, the nanotube structures can not be synthesized at the outermost surface but amorphous carbon should be produced as well as the case of the Fe plate surface 
as in Fig. 2.

When SUS316 surface was entirely covered with oxidized Fe by $2 \mathrm{~h}$ duration of oxidation step, an unique mushroom structure was produced as shown in Fig. 5b and 5c. It can be seen that amorphous carbons were lift up by MWCNT bundles, forming this mushroom-like structure. The formation mechanism of the mushroom structure can be explained by considering the effects of the Fe diffusion as depicted in Fig. 8. When the concentration of Fe becomes excessively high at the SUS316 surface by the Fe diffusion through the Cr-rich layer as mentioned above, this outermost surface is entirely covered with Fe film, and this Fe layer will produce amorphous carbon. When the amorphous carbon with this Fe-rich layer is peeled off, MWCNTs are produced with catalytic growth on Fe nanoparticles on Cr-rich layer remaining in deeper locations in SUS316 substrate. By this mechanism, the mushroom structure can be formed. The application of this mushroom structure should be investigated in future. At this stage, we consider that this structure might be useful for magnetic sensor due to the combination of large surface area of MWCNTs and magnetic property of the Fe-rich layer supported by the MWCNT stems.

Also the duration of reduction step was varied to observe its influence on MWCNT growth at the surface of SUS316. As well as in the observation on the influence of the oxidation duration, the temperatures for the steps of the oxidation, the reduction, and the CVD were 800,700 , and $700{ }^{\circ} \mathrm{C}$, respectively. Two examples of SEM images of the MWCNTs synthesized under such conditions are shown in Fig. 9. In these images, aligned MWCNTs grown in perpendicular to the substrate surface can 
be observed. In this figure, the thickness of the MWCNT film formed thereon by 120 min of reduction step turned to be significantly larger than by $3 \mathrm{~min}$. The average thickness of the MWCNT film was measured by SEM observation, and the results were summarized by plotting in Fig. 10a. The thickness of MWCNT film initially was approximately $17 \mu \mathrm{m}$, and this thickness tended to increase with the reduction duration up to $120 \mathrm{~min}$. After reaching approximately $36 \mu \mathrm{m}$ at $120 \mathrm{~min}$, the film thickness decreased with the reduction duration to approximately $9 \mu \mathrm{m}$ at $240 \mathrm{~min}$. This result indicates that an appropriate reduction extent can make the suitable structures in the alloy surface. The reason why there is such an optimized reduction duration has not yet been clarified. Nevertheless, it would be considered that increase of MWCNT film thickness by increasing reduction duration in early time range may be caused by cleaning the surfaces of the catalytic Fe nanoparticles. The decrease of MWCNT film thickness by increasing reduction duration in later time range would be due to formation of defects in Cr-rich layer on SUS316 surface so that Fe nanoparticles may not be stably supported in the CVD process for MWCNT growth. Further investigation on the SUS316 surfaces should be carried out to clarify this mechanism.

It was observed that, unlike the influence of the oxidation duration, the diameter of MWCNTs was not affected by the reduction duration as shown in Fig. 10b. Raman spectra were obtained to observe the influence of reduction duration, but no significant influence of the reduction duration was observed. Thus, the reduction duration affected only the thickness of MWCNT film. From this result, the layer of oxidized $\mathrm{Cr}$ is considered to inhibit the diffusion of $\mathrm{Fe}$ in reductive environment with $\mathrm{H}_{2}$, 
and the size of the Fe nanoparticles supported on Cr-rich layer may not change during the reduction step.

\section{Conclusions}

MWCNTs were directly synthesized on the surface of the plates of six kinds of industrial alloys, SUS316, JIS-FCH2, Invar, Permalloy, Inconel, and Nichrome, and three kinds of pure metals, Fe, Ni, and $\mathrm{Cr}$ by a simple reduction-oxidation method from ethylene as the carbon source. From the comparison among the substrates used for the experiments, $\mathrm{Cr}$ is considered to be a key component to realize the catalytic growth of MWCNTs. Using SUS316, the influence of the durations of the oxidation step and the reduction step on the product structures was investigated. The diameter of MWCNTs can be affected by oxidation duration, and the thickness of the MWCNT film was affected by the reduction duration. The XPS analysis suggested that diffusion of Fe through Cr-rich layer toward the outermost surface in the oxidation step should lead to increase of the diameter of MWCNTs, and excess Fe covering the Cr-rich surface generated by excess oxidation duration resulted in the formation of a unique mushroom structure. The Cr-rich layer should be stable against this Fe diffusion in the reduction step so that the diameter of resulted MWCNTs was independent of the reduction duration.

\section{References}

[1] S. Iijima, Helical microtubes of graphite carbon, Nature 354 (1991) 56-58.

[2] M. Bissett, A. Barlow, C. Shearer, J. Quinton, J.G. Shapter, Comparison of carbon nanotube 
modified electrodes for photovoltaic devices, Carbon 50 (2012) 2431-2441.

[3] C.-S. Oh, S.D. Bhagat, Y.-H. Kim, B.-C. Woo, Y.S. Ahn, S.-I. Lim, Comparative studies on the magnetic separation of carbon nanotubes and carbon nanofibers suspended in aqueous solution, J.

Chem. Eng. Jpn. 41 (2008) 627-630.

[4] M.V. Jose, S. Marx, H. Murata, R.R. Koepsel, A.J. Russell, Direct electron transfer in a mediator-free glucose oxidase-based carbon nanotube-coated biosensor, Carbon 50 (2012) $4010-4020$.

[5] M. Tunckol, J. Durand, P. Serp, Carbon nanomaterial-ionic liquid hybrids, Carbon 50 (2012) 4303-34.

[6] L. Song, G. Toth, R. Vajtai, M. Endo, P.M. Ajayan, Fabrication and characterization of single-walled carbon nanotube fiber for electronics applications, Carbon 50 (2012) 5521-5524.

[7] H. Yang, M.E. Itkis, R. Moriya, C. Rettner, J.-S. Jeong, D.S. Pickard, R.C. Haddon, S.S.P. Parkin, Nonlocal spin transport in single-walled carbon nanotube networks, Phys. Rev. B 85 (2012) 052401-1-5.

[8] M.C. Gordillo, J. Boronat, ${ }^{4}$ He adsorbed outside a single carbon nanotube, Phys. Rev. B 86 (2012) 165409-1-6.

[9] J. Jia, S.-P. Ju, D. Shi, K.-F. Lin, Electrical transport through heterojunctions of single-walled carbon/silicon carbide/carbon nanotubes, J. Appl. Phys. 111 (2012) 013704-1-6.

[10] A. Cao, J. Qu, Size dependent thermal conductivity of single-walled carbon nanotubes, J. Appl. 
Phys. 112 (2012) 013503-1-9.

[11] C.A. Kuntscher, A. Abouelsayed, K. Thirunavukkuarasu, F. Hennrich, Y. Iwasa, Pressure effects on unoriented and oriented single-walled carbon nanotube films studied by infrared microscopy, J.

Appl. Phys. 111 (2012) 112614-1-5.

[12] B.C. Gupta, S. Konar, P. Jena, Electrical transition of $(3,3)$ carbon nanotube on patterned hydrogen terminated Si(001)-2 × 1 driven by electric field, J. Appl. Phys. 111 (2012) 123717-1-7.

[13] S. Iijima, T. Ichihashi, Single-shell carbon nanotubes of 1-nm diameter, Nature 363 (1993) 603-605.

[14] J.L. Hutchison, N.A. Kiselev, E.P. Krinichnaya, A.V. Krestinin, R.O. Loutfy, A.P. Morawsky, V.E. Muradyan, E.D. Obraztsova, J. Sloan, S.V. Terekhov, D.N. Zakharov, Double-walled carbon nanotubes fabricated by a hydrogen arc discharge method, Carbon 39 (2001) 761-770.

[15] N. Sano, H. Wang, M. Chhowalla, I. Alexandrou, G.A.J. Amaratunga, Synthesis of carbon 'onions' in water, Nature 414 (2001) 506-507.

[16] D. Bera, S.C. Kuiry, M. McCutchen, S. Seal, H. Heinrich, G.C. Slane, In situ synthesis of carbon nanotubes decorated with palladium nanoparticles using arc-discharge in solution method, J. Appl. Phys. 96 (2004) 5152-1-6.

[17] M. Kundrapu, J. Li, A. Shashurin, M. Keidar, A model of carbon nanotube synthesis in arc discharge plasmas, J. Phys. D: Appl. Phys. 45 (2012) 315305.

[18] M. Yudasaka, T. Komatsu, T. Ichihashi, S. Iijima, Single-wall carbon nanotube formation by laser 
ablation using double-targets of carbon and metal, Chem. Phys. Lett. 278 (1997) 102-106.

[19] R.S. Lee, H.J. Kim, J.E. Fischer, A. Thess, R.E. Smalley. Conductivity enhancement in single-walled carbon nanotube bundles doped with K and Br, Nature 388 (1997) 255-257.

[20] N. Chiodarelli, O. Richard, H. Bender, M. Heyns, S.D. Gendt, G. Groeseneken, P. M. Vereecken, Correlation between number of walls and diameter in multiwall carbon nanotubes grown by chemical vapor deposition, Carbon 50 (2012) 1748-1752.

[21] S. Corthals, J.V. Noyen, J. Geboers, T. Vosch, D. Liang, X. Ke, J. Hofkens, G. V. Tendeloo, P. Jacobs, B. Sels, The beneficial effect of $\mathrm{CO}_{2}$ in the low temperature synthesis of high quality carbon nanofibers and thin multiwalled carbon nanotubes from $\mathrm{CH}_{4}$ over Ni catalysts, Carbon 50 (2012) 372-384.

[22] Y. Yun, R. Gollapudi, V. Shanov, M.J. Schulz, Z. Dong, A. Jazieh, W.R. Heineman, H.B. Halsall, D.K. Wong, A. Bange, Y. Tu, S. Subramaniam. Carbon nanotubes grown on stainless steel to form plate and probe electrodes for chemical/biological sensing. J. Nanosci. Nanotechnol. 7 (2007) 891-897.

[23] M. He, P.V. Fedotov, E.D. Obraztsova, V. Viitanen, J. Sainio, H. Jiang, E. I. Kauppinen, M. Niemelä, J. Lehtonen, Chiral-selective growth of single-walled carbon nanotubes on stainless steel wires, Carbon 50 (2012) 4294-4297.

[24] C.E. Baddour, F. Fadlallah, D. Nasuhoglu, R. Mitra, L. Vandsburger, J.-L. Meunier, A simple thermal CVD method for carbon nanotube synthesis on stainless steel 304 without the addition of an 
external catalyst, Carbon 47 (2008) 313-318.

[25] N. Sano, Y. Hori, S. Yamamoto, H. Tamon, A simple oxidation-reduction process for the activation of a stainless steel surface to synthesize multi-walled carbon nanotubes and its application to phenol degradation in water, Carbon 50 (2012) 115-122.

[26] N. Sano, S. Yamamoto, H. Tamon, Uniform synthesis of multi-walled carbon nanotubes in a stainless steel porous block, Carbon 50 (2012) 5628-5630.

[27] Y. Jung, J. Song, W. Huh, D. Cho, Y. Jeong, Controlling the crystalline quality of carbon nanotubes with processing parameters from chemical vapor deposition synthesis, Chem. Eng. J. 228 (2013) 1050-1056.

[28] Q.-Y. Li, Z.-S. Li, L. Lin, X.Y. Wang, Y.-F. Wang, C.-H. Zhang, H.-Q. Wang, Facile synthesis of activated carbon/carbon nanotubes compound for supercapacitor application, Chem. Eng. J. 156 (2010) 500-504.

[29] S. R. Bakshi, D. Lahiri and A. Agarwal, Carbon nanotube reinforced metal matrix composites - a review, Int. Mater. Rev. 55 (2010) 41-64.

[30] M. Endo, T. Takeuchi, S. Igarashi, K. Kobori, M. Shiraishi, H.W. Kroto, The production and structure of pyrolytic carbon nanotubes (PCNTs), J. Phys. Chem. Solids 54 (1993) 1841-1848.

[31] A.C.S. Sabioni, A.M. Huntz, F. Silva, F. Jomard, Diffusion of iron in $\mathrm{Cr}_{2} \mathrm{O}_{3}$ : polycrystals and thin films, Mater. Sci. Eng. A 392 (2005) 254-261. 


\section{Figure captions}

Fig. 1. Components in alloys used in the present study. Concentrations were analyzed by EDX.

Fig. 2. SEM images of the surfaces of substrates after three steps (oxidation step, reduction step, and CVD step) on which MWCNTs were not formed by synthesis conditions in the present study.

Fig. 3. SEM images of the surfaces of substrates after three steps (oxidation step, reduction step, and CVD step) on which MWCNTs were successfully formed by synthesis conditions in the present study.

Fig. 4. Raman spectra of as-grown MWCNTs synthesized on (a) SUS316, (b) Nichrome, (c) Inconel, and (d) FCH2.

Fig. 5. SEM images of MWCNTs synthesized by two oxidation durations (a) 5 min and (b, c) 120 min.

Reduction duration was constant at $60 \mathrm{~min}$. The image of (c) is expansion of square in (b).

Fig. 6. Influence of oxidation duration on average diameter of MWCNTs synthesized on SUS316. Reduction duration was constant at $60 \mathrm{~min}$. Inset shows an example TEM image of MWCNTs produced by the present study.

Fig. 7. Component distributions determined by XPS analysis in SUS316 after two oxidation durations (a) 60 min and (b) 120 min.

Fig. 8. Explanatory schematic image of formation mechanism of MWCNT and mushroom structures on the surface of SUS316.

Fig. 9. SEM images of MWCNTs synthesized by two reduction durations (a) 3 min and (b) $120 \mathrm{~min}$. Oxidation duration was constant at $60 \mathrm{~min}$.

Fig. 10. Influence of reduction duration on thickness of MWCNT film and average diameter of MWCNTs. 
Oxidation duration was constant at $60 \mathrm{~min}$.

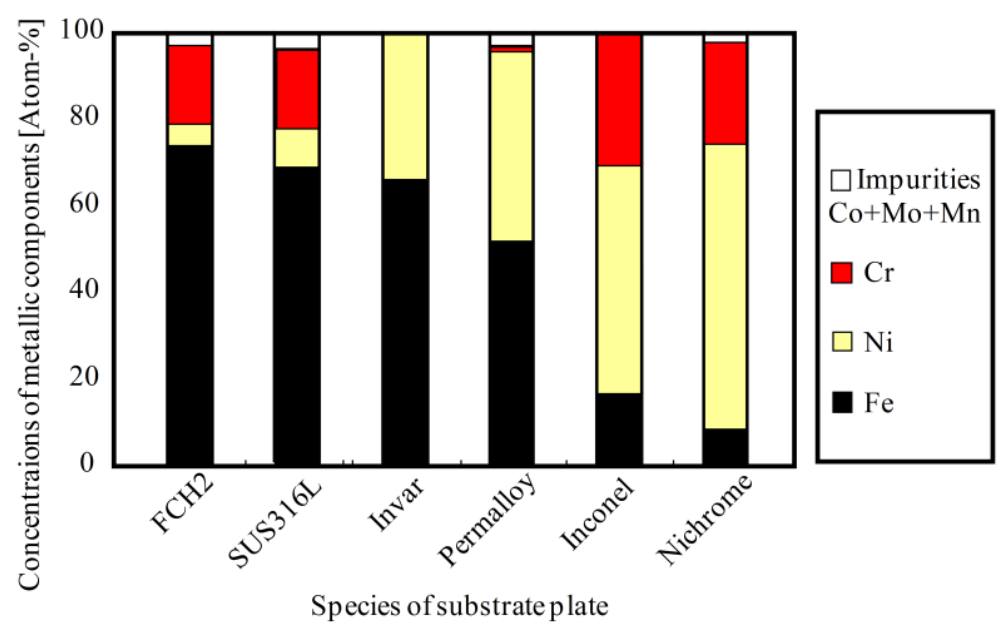

Fig. 1. Components in alloys used in the present study. Concentrations were analyzed by EDX. 


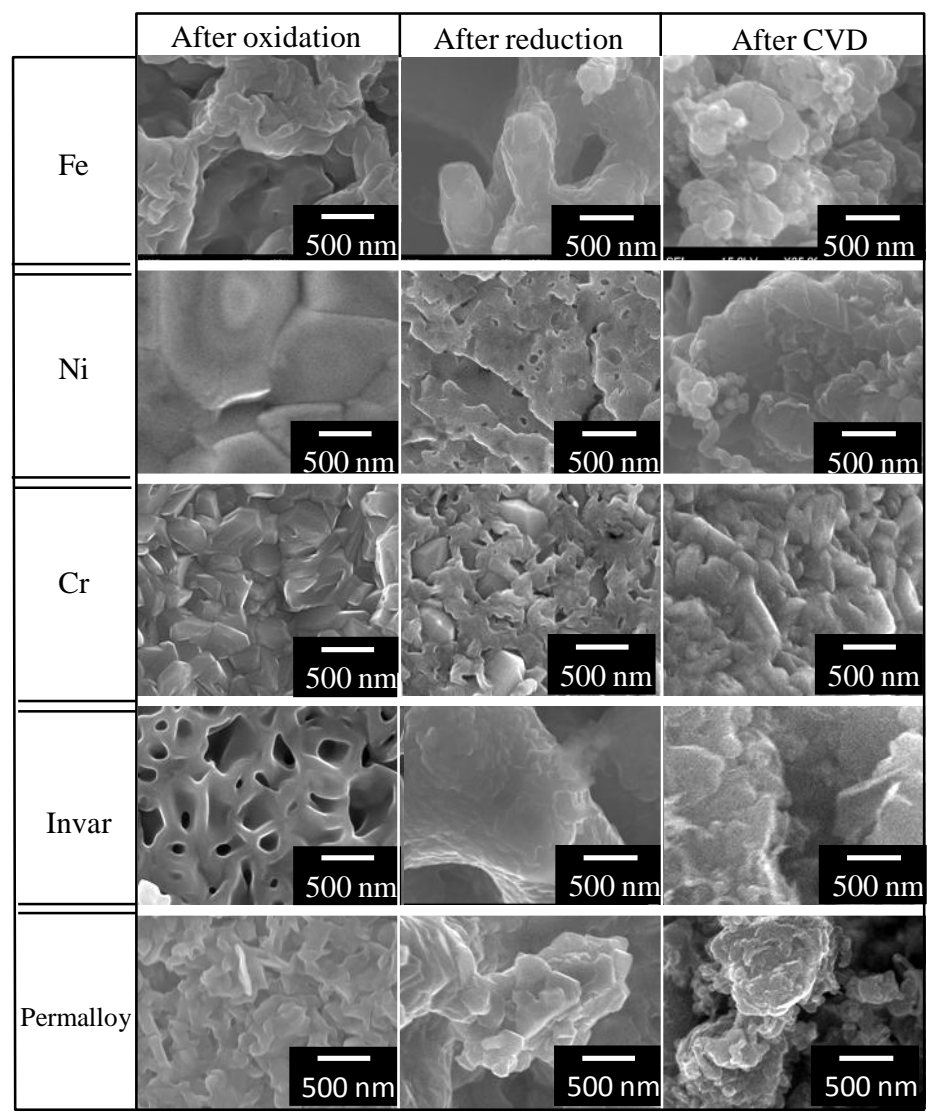

Fig. 2. SEM images of the surfaces of substrates after three steps (oxidation step, reduction step, and CVD step) on which MWCNTs were not formed by synthesis conditions in the present study. 


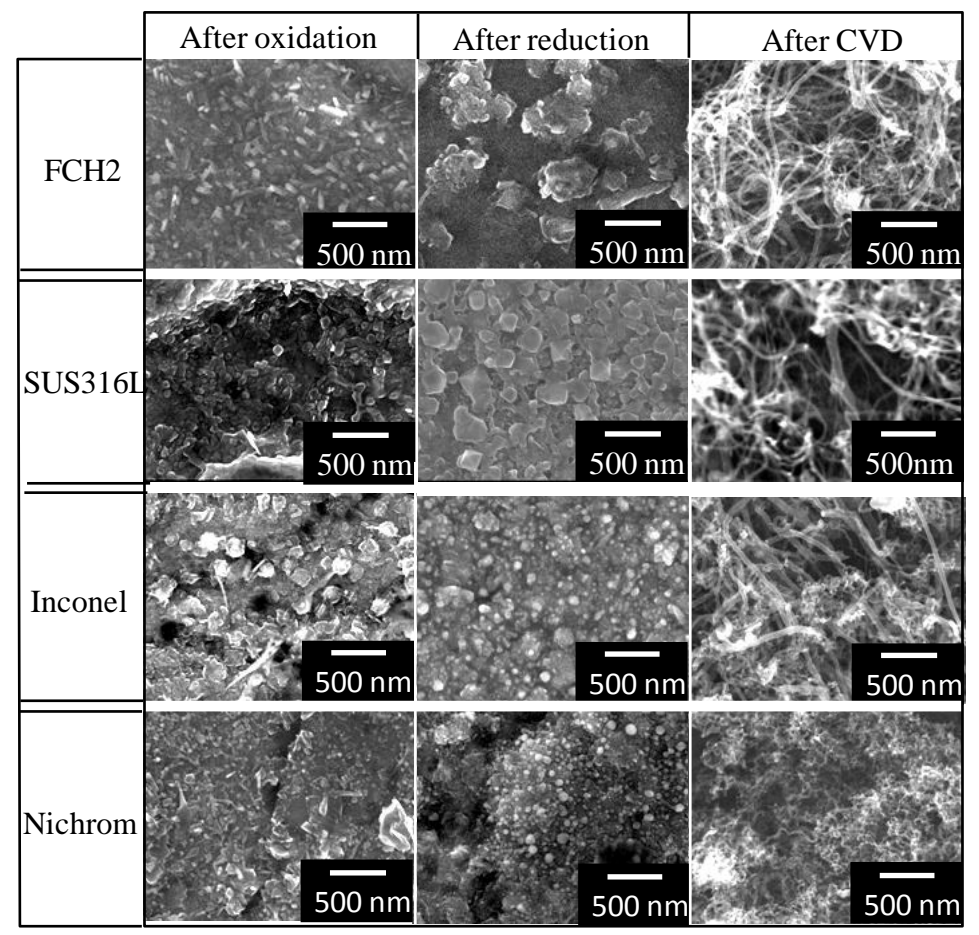

Fig. 3. SEM images of the surfaces of substrates after three steps (oxidation step, reduction step, and CVD step) on which MWCNTs were successfully formed by synthesis conditions in the present study.

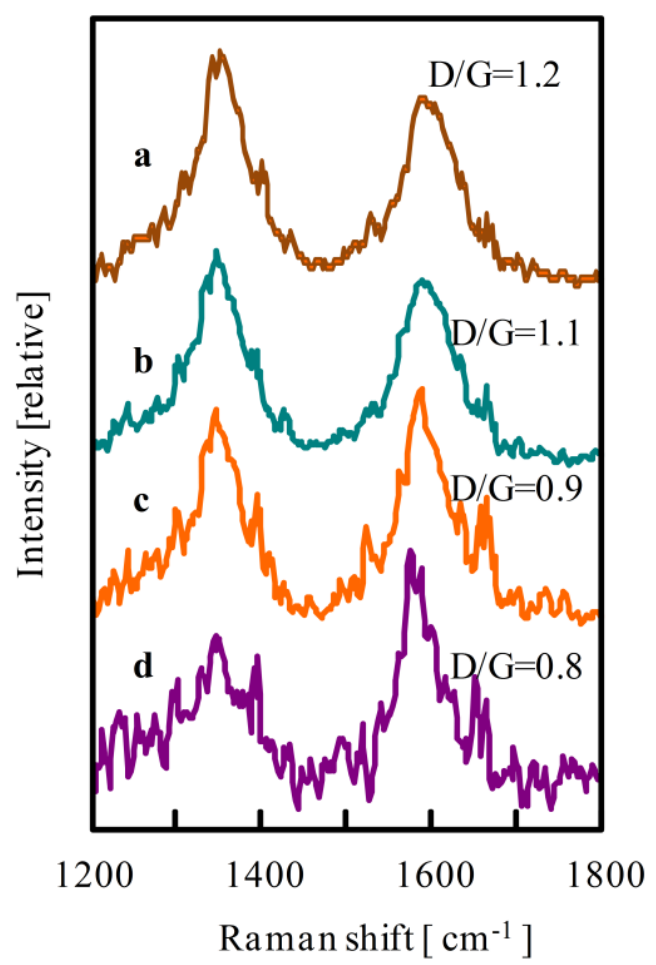

Fig. 4. Raman spectra of as-grown MWCNTs synthesized on (a) SUS316, (b) Nichrome, (c) Inconel, and (d) FCH2. 


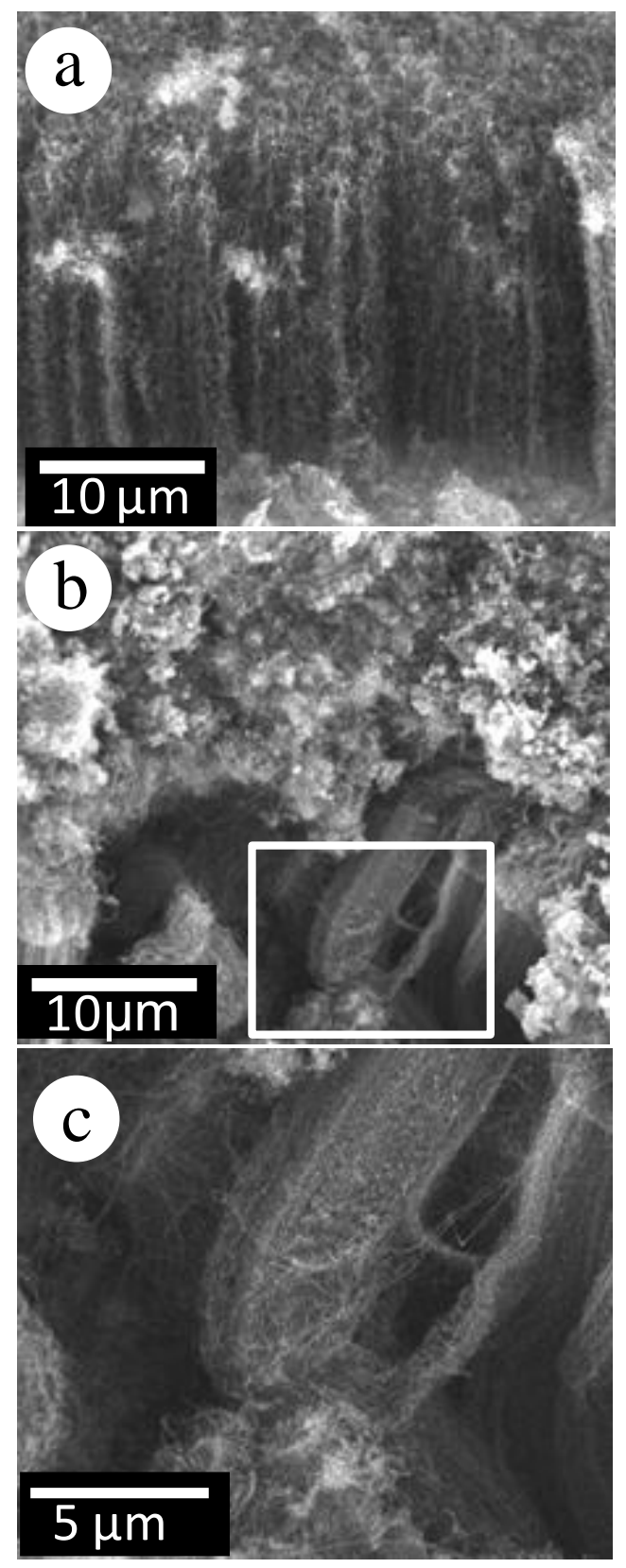

Fig. 5. SEM images of MWCNTs synthesized by two oxidation durations (a) 5 min and (b, c) 120 min.

Reduction duration was constant at $60 \mathrm{~min}$. The image of (c) is expansion of square in (b). 


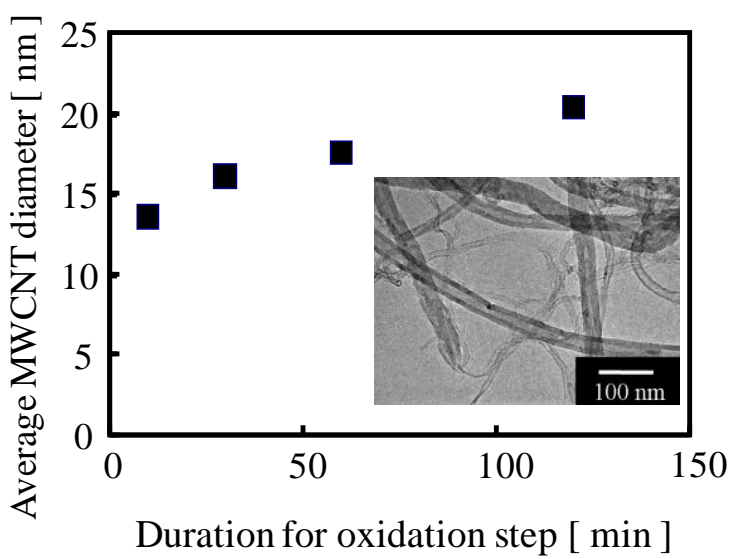

Fig. 6. Influence of oxidation duration on average diameter of MWCNTs synthesized on SUS316. Reduction duration was constant at $60 \mathrm{~min}$. Inset shows an example TEM image of MWCNTs produced by the present study.
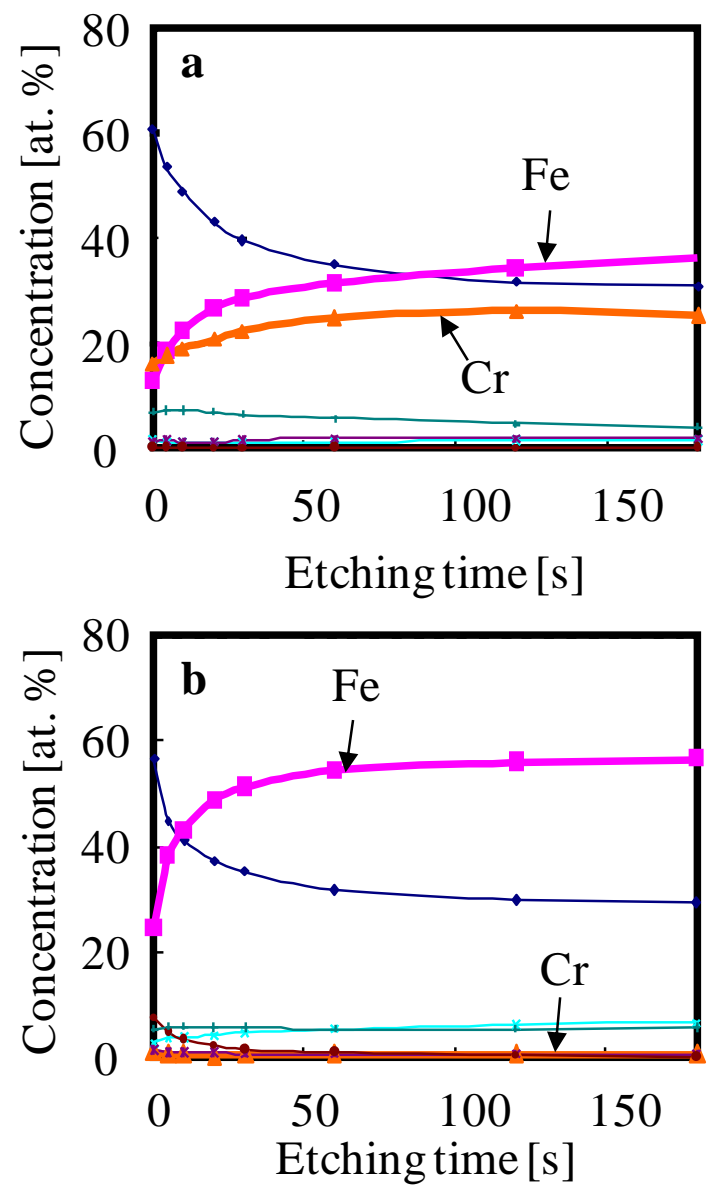

Fig. 7. Component distributions in SUS316 after two oxidation durations (a) 60 min and (b) $120 \mathrm{~min}$. 


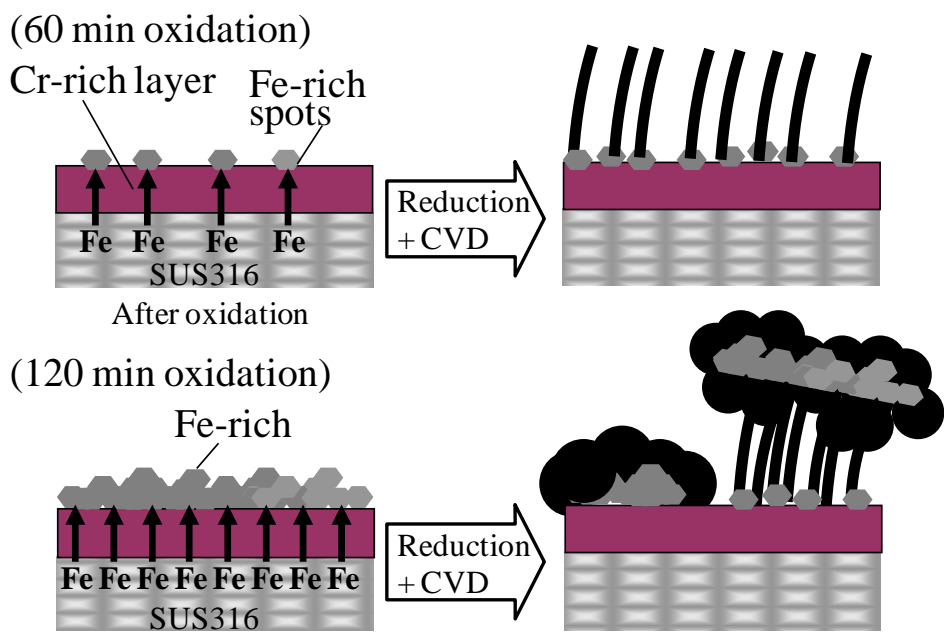

After excessive oxidation

Fig. 8. Explanatory schematic image of formation mechanism of MWCNT and mushroom structures on the surface of SUS316.
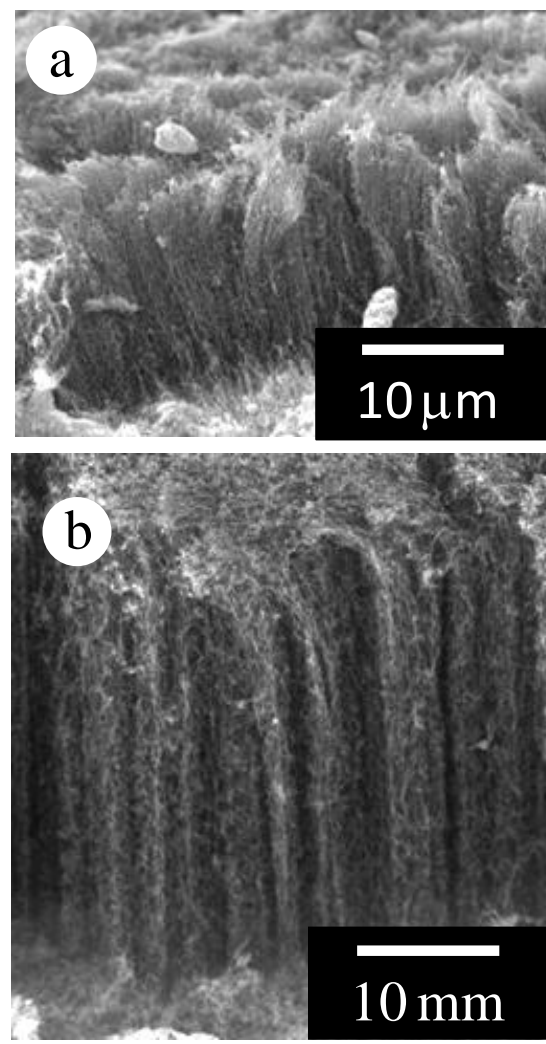

Fig. 9. SEM images of MWCNTs synthesized by two reduction durations (a) 3 min and (b) 120 min.

Oxidation duration was constant at $60 \mathrm{~min}$. 

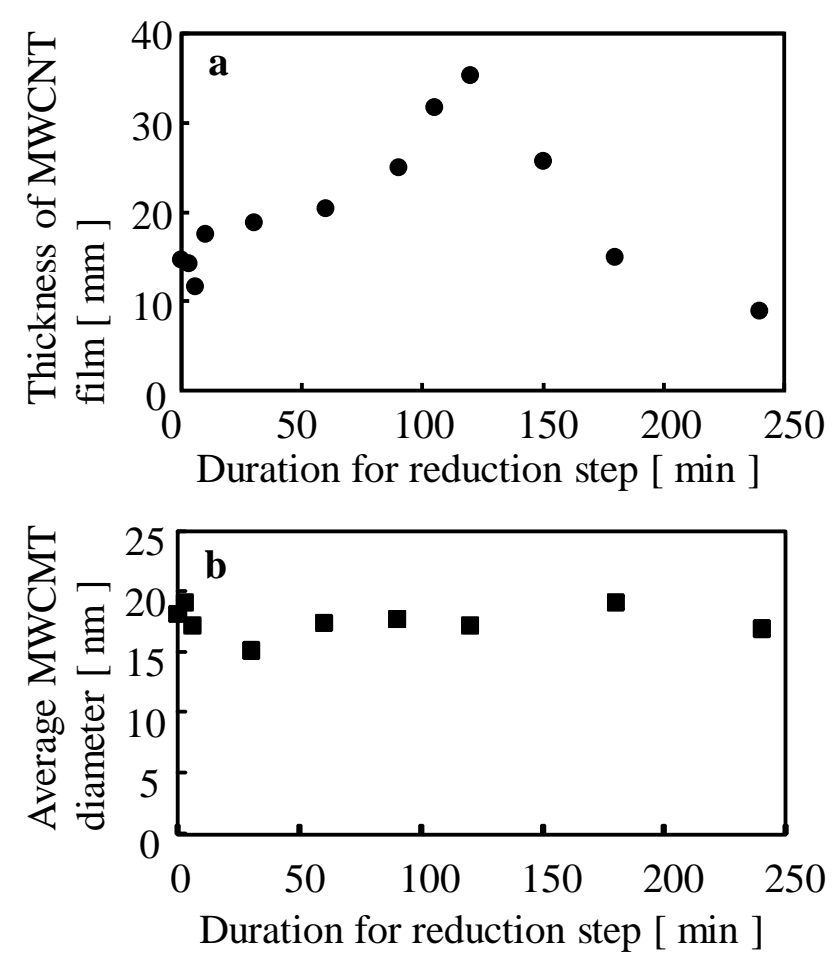

Fig. 10. Influence of reduction duration on thickness of MWCNT film and average diameter of MWCNTs.

Oxidation duration was constant at $60 \mathrm{~min}$. 